Check for updates

Cite this: RSC Adv., 2019, 9, 34814

\title{
Cationization of Eucalyptus wood waste pulps with diverse lignin contents for potential application in colored wastewater treatment
}

\author{
Kinga Grenda, (D) ab José A. F. Gamelas, (D) a Julien Arnold, ${ }^{\text {b }}$ Olivier J. Cayre ${ }^{c}$ \\ and Maria G. Rasteiro (D) *a
}

Modification of cellulosic-rich materials such as Eucalyptus wood waste and production of cellulose-based polyelectrolytes (PELS) presents several advantages for a variety of applications, when compared to the utilization of synthetic PELs, due to the nature, availability, high biodegradability and low or no toxicity of cellulosic materials. Moreover, valorization of the cellulosic waste itself to provide end products with higher added value is also an important aspect. In the present work, the objective was to evaluate the possibility of cationizing more complex and heterogeneous chemical pulps, obtained from Eucalyptus wood waste, with different cellulose purity and a relatively high lignin content (up to 4.5\%). A two-step reaction (with sodium periodate and Girard's reagent T) was employed and a range of cellulose-based cationic polyelectrolytes were produced with different degrees of substitution. The final products were characterized by several analytical techniques and the bio-PELs with the highest and the lowest substitution degree by cationic groups were evaluated in a new application, as flocculants in the decoloration of model effluents, bentonite having been used as an inorganic aid. Also, possible mechanisms of flocculation were discussed and the results compared with those of a synthetic flocculant, often used in these treatments, cationic polyacrylamide. Lignocellulosic-PELs proved to be very favorable eco-friendly flocculation agents for the decoloration of dye-containing waters with potential application in several industries.

Received 25th July 2019

Accepted 16th October 2019

DOI: $10.1039 / c 9 r a 05757 a$

rsc.li/rsc-advances

\section{Introduction}

Flocculation and coagulation are traditional techniques for effective wastewater treatment, usually making use of an extensive variety of synthetic materials for this purpose. However, due to low biodegradability, being harsh to the environment or to health, there is a strong need for the replacement of oil-based additives by more eco-friendly solutions. In fact, there is an increasing interest in the development of low-cost, cellulosic biomass-based materials, ${ }^{1}$ for effluent treatment from various industries. ${ }^{2}$ Among other natural sources, wood and its wastes are one of the most promising and attractive feedstocks for the extraction and production of chemicals for several applications. Nevertheless, the insolubility in water and low chemical reactivity are the main drawbacks to the application of lignocellulosic materials in flocculation processes in various industries. To overcome those limitations, several

${ }^{a}$ Chemical Engineering Department, CIEPQPF, University of Coimbra, Pólo II, Rua Sílvio Lima, 3030-790 Coimbra, Portugal..E-mail:mgr@eq.uc.pt

${ }^{b} A q u a+T e c h$ Specialities SA, Chemin du Chalet-du-Bac 4, Avully, 1237, Geneva, Switzerland

${ }^{c}$ School of Chemical and Process Engineering, University of Leeds, Woodhouse Lane, Leeds LS2 9JT, UK specific modifications of cellulose have been developed, namely by introduction of charged groups into the polymeric backbone.

Bearing in mind that cationic synthetic polymers are more frequently used in the wastewater treatment than the anionic ones, introduction of positively charged groups into the cellulosic backbone will be addressed in this work. Among several possibilities for cationization of cellulose, three main routes of cellulose modification can be identified. ${ }^{3}$ The first one is based on a direct cellulose modification by (i) dissolution of short chain cellulose molecules in aqueous solutions of e.g. $\mathrm{NaOH} /$ urea, $\mathrm{NaOH} /$ thiourea or $\mathrm{LiOH} / \mathrm{urea}$, which are pre-cooled to zero degrees, followed by (ii) cationization in homogeneous medium with (3-chloro-2-hydroxypropyl)trimethylammonium chloride (CHPTAC), as described in the literature., ${ }^{4,5}$ Another approach refers to cationization of pre-modified cellulose, by using dialdehyde cellulose ${ }^{6,7}$ or cellulose acetate, ${ }^{8}$ among other materials. The third approach involves introduction of monomeric or polymeric cationizing agents into the cellulose backbone by graft copolymerization. ${ }^{9}$ However, when speaking of cationization and bearing in mind potential application in flocculation, it is very important to obtain a final water-soluble cellulose derivative with the charged groups spread effectively among the polymeric backbone. The quaternary ammonium (positively charged) groups are very promising candidates for 
introduction of cationicity in the cellulose backbone, as they are widely present in successfully applied synthetic flocculants. It is possible to introduce those groups by performing reactions with appropriate chemicals. Considering the several existing possibilities, the route based on the pre-modification to dialdehyde cellulose before cationization, ${ }^{10,11}$ is very effective. In this reaction, a high modification degree can be achieved, since two aldehyde groups are introduced per anhydroglucose (AGU) unit, which allows to obtain highly modified end products. The selective oxidation with periodate partially destroys the crystalline cellulose structure and decreases the polymerization degree. $^{10,12}$ Still, this reaction allows keeping to a reasonable extent the mechanical and morphological properties of the starting material, ${ }^{13}$ even if introduction of highly reactive aldehyde groups in the cellulose chain (two per AGU unit at C-2 and $\mathrm{C}-3$ positions), by opening the AGU unit at the $\mathrm{C} 2-\mathrm{C} 3$ linkage, occurs. Several reaction parameters, such as: periodate/AGU ratio, ${ }^{14}$ temperature, ${ }^{6,10} \mathrm{pH},{ }^{10}$ oxidation time ${ }^{15}$ or even exposure to the light (as periodate oxidation is a highly light sensitive process) ${ }^{11}$ may influence the properties of the obtained dialdehyde cellulose (DAC) products. This process can be also affected by the raw material composition and its particle size. ${ }^{13}$ Nevertheless, several improvements to the reaction kinetics have been described, such as the introduction of metal salts ( $\mathrm{LiCl}, \mathrm{ZnCl}_{2}, \mathrm{CaCl}_{2}, \mathrm{MgCl}_{2}$ or $\left.\mathrm{NaCl}\right)^{11}$ allowing to work at higher temperatures and thus reducing the reaction time, or still the simultaneous use of ultra-sonication ${ }^{16}$ leading to faster kinetics and highly oxidized products. However, it should be noted that uncontrolled reaction conditions may cause over-oxidation, ${ }^{\mathbf{1 0}}$ which leads to full dissolution of the cellulose polymer and noneffective production of dialdehyde groups (DAC with low aldehyde content).

Highly charged, cationic cellulose-based polyelectrolytes (PELs) from birch wood pulp were produced by Sirviö et al. ${ }^{6}$ and Liimatainen $e t a .^{7}$ The raw material was firstly oxidized with periodate, leading to the formation of dialdehyde cellulose. The cationic PELs were then obtained by the DAC modification using Girard's reagent T (GT), which leads to an imine bond resulting in positively charged quaternary ammonium groups being introduced into the cellulose backbone. This type of modification allows to introduce more than one cationic group per AGU. Products obtained in such a way are thus characterized by a high degree of substitution, high ionic character and consequently high charge density and water solubility at room temperature.

Sirviö et al. ${ }^{6}$ evaluated the influence of different reaction parameters on the final characteristics of the obtained products. The cationization was performed with 7.8 of GT/aldehyde molar ratio, using $\mathrm{HCl}$ as a catalyst $(\mathrm{pH} 4.5)$. Carrying out the reaction at $20^{\circ} \mathrm{C}$ during $1 \mathrm{~h}$ allowed to obtain a product with cationic groups content of $2.85 \mathrm{mmol} \mathrm{g}^{-1}$. However, cationicity would increase from 2.85 to $4.27 \mathrm{mmol} \mathrm{g}^{-1}$, if the reaction time increased from $1 \mathrm{~h}$ to $72 \mathrm{~h}$. In order to decrease the reaction time but still obtain highly charged PELs, higher temperatures needed to be applied, and, e.g. after $3 \mathrm{~h}$ at $60{ }^{\circ} \mathrm{C}$, a PEL with $4.09 \mathrm{mmol} \mathrm{g}^{-1}$ of cationic groups content was obtained. Additionally, the ratio of GT to dialdehyde had also high impact on the final cationicity of the obtained products. Moreover, it was observed that with high aldehyde content in DAC, while using a large excess of GT, it was possible to obtain higher cationic contents at lower temperatures. ${ }^{6}$ The quaternary ammonium modification of cellulose produced a novel biopolymeric flocculation agent that showed a good performance on the flocculation of calcium carbonate suspensions, due to charge neutralization mechanism. In complementary studies by Liimatainen et al. ${ }^{7}$ with similar cationic cellulose-based flocculants obtained by GT modification of DAC, a flocculation efficiency on kaolin suspensions similar to that of a synthetic reference (cPAM - cationic polyacrylamide) was reported; however flocs obtained with the bio-flocculants showed to be smaller in size. The obtained products showed high flocculation ability in neutral or acidic solutions, but with the decrease of acidity $(\mathrm{pH}>8.5-9)$ the performance also decreased.

Several studies have been found in the literature about cationization of cellulose using periodate oxidation followed by the GT reaction, ${ }^{6,7}$ but as far as we know, these reactions have never been performed starting from highly complex cellulosic materials, with a high lignin content. Also, in those studies, the obtained products have not been used to valorize cellulosic wastes. Thus, the aim of the present study is to establish a cationization procedure to successfully prepare water-soluble, lignocellulose-based flocculation agents, with different charge density (substitution degree), from more complex wood-based raw materials (pulps with different lignin content and obtained by different procedures). A sequence of two reactions: oxidation followed by cationization was proposed. For that, optimized conditions were established, starting from a reference raw material with a negligible lignin content (Eucalyptus bleached pulp), which were afterwards, applied to the other lignocellulosic materials having distinct kappa number, and obtained applying or not a wood pre-extraction with hot water. The prepared cationic natural-based PELs with the highest and the lowest degree of substitution, obtained from each starting material, were evaluated in an application not previously described in the literature, as natural flocculants in the treatment of model colored effluents (dyes).

Dye-containing wastewaters are very harsh and difficult effluents to treat because of the recalcitrant nature of most of the dyes. ${ }^{17,18}$ These effluents, mainly produced by the textile industry, but also in processes of paper, leather or food coloration, comprise a large variety of dyes, such as the basic (cationic) dyes, acid dyes, direct dyes and the reactive dyes. ${ }^{19}$ Besides color, dyes add a high level of biochemical oxygen demand and chemical oxygen demand to the effluent, and, additionally, some of them can also be toxic. ${ }^{20}$ Thus, their treatment using effective and environmentally friendly methods is desirable.

\section{Materials and methods}

\section{Raw materials}

Eucalyptus globulus industrial wood chips wastes, with a high size heterogeneity, supplied by The Navigator Company (Portugal), were used as lignocellulosic raw material. These were 
further processed using hot water extraction and kraft pulping. The typical chemical composition (wt\%, on a dry basis) is summarized in Table 1.

Eucalyptus globulus industrial bleached kraft pulp, used as cellulose fiber source and reference sample of insignificant lignin content, was supplied by The Navigator Company (Portugal). This pulp (hereafter mentioned as cellulosic pulp or $\mathrm{C}_{\mathrm{p}}$ ) contained 85 wt $\%$ (on oven-dry pulp weight) of cellulose, $14 \mathrm{wt} \%$ of glucuronoxylan (hemicellulose) and about $1 \mathrm{wt} \%$ of other components (ashes, extractives) where lignin content is below $0.1 \mathrm{wt} \%$.

\section{Production of pulps with diverse lignin content}

The Eucalyptus wood wastes with high size heterogeneity were treated using two different routes, as described in Fig. 1. The first one involved two steps: hot water extraction followed by kraft cooking. The second route was a one-step treatment involving only kraft cooking.

Hot water extraction. The Eucalyptus wood chips wastes were submitted to hot water extraction in a rotary digester equipped with 4 independent $1.5 \mathrm{~L}$ vessels (Apineq). Each vessel was loaded with $200 \mathrm{~g}$ of wood chips (dry basis) and $800 \mathrm{~mL}$ of water (water/wood ratio of $4: 1$ ). The reactor heating rate was $1{ }^{\circ} \mathrm{C} \mathrm{min}{ }^{-1}$, the maximum temperature was $160{ }^{\circ} \mathrm{C}$, the time to reach maximum temperature $143 \mathrm{~min}$, and the time at maximum temperature $30 \mathrm{~min}$. After cooling, the hot water extracted chips were washed with a large amount of water and air-dried. The extracted chips were further used for kraft cooking. With hot water extraction, hemicelluloses are partially removed together with water soluble constituents.

Kraft cooking. The cooking liquor used in the kraft pulping was prepared by introducing into a flask $8 \mathrm{~g}$ of sodium carbonate, $46 \mathrm{~g}$ of sodium hydroxide and $29.5 \mathrm{~g}$ of sodium sulphide, followed by dilution with $800 \mathrm{~mL}$ of deionized water.

Eucalyptus wood chips wastes were submitted to kraft pulping in the same rotary digester referred above, equipped with 4 independent 1.5 L vessels (Apineq). Each vessel was loaded with $200 \mathrm{~g}$ of wood chips (dry basis) and $700 \mathrm{~mL}$ of cooking liquor (liquor-to-wood ratio of 3.5). The reactor heating rate was $1{ }^{\circ} \mathrm{C} \mathrm{min}{ }^{-1}$, the maximum temperature was $160{ }^{\circ} \mathrm{C}$, the time to reach maximum temperature $141 \mathrm{~min}$, and the time at maximum temperature $60 \mathrm{~min}$. At the end of cooking, the produced pulps were thoroughly washed with a large amount of

Table 1 Eucalyptus globulus chemical composition range of values ${ }^{21}$

\begin{tabular}{lcc}
\hline & Max. (wt\%) & Min. (wt\%) \\
\hline Glucans & 53.4 & 41.7 \\
Xylans & 16.8 & 11.7 \\
Mannans & 2.6 & 0.7 \\
Cellulose & 51.3 & 40.6 \\
Insoluble lignin & 23.2 & 18.2 \\
Soluble lignin & 6.1 & 3.5 \\
Total lignin & 28.5 & 21.9 \\
Extractives & 6.0 & 1.3
\end{tabular}

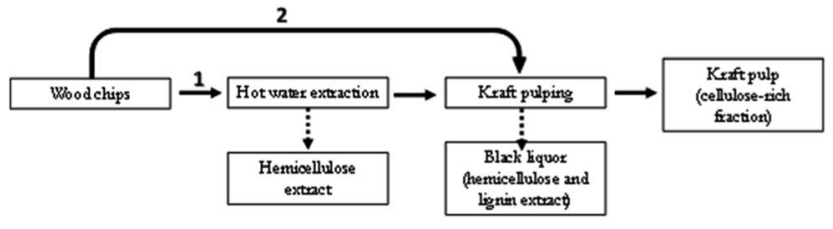

Fig. 1 Scheme of Eucalyptus wood wastes treatment.

water and then dried. Two different alkaline charges were used in the cooking's (see Table 2). Cooking of the previously hot water extracted wood chips was also performed, following the same methodology. The kraft cooking of the hot water extracted chips was done after air-drying the samples. Kappa numbers of the final pulps were measured according to TAPPI Standard T236 om-99. The results of the cooking experiments, as well as the conditions used are summarized in Table 2. The kraft pulps were analyzed for sugars and lignin content (Klason and acidsoluble lignin were determined using the TAPPI Standards T 222 om and T UM 250, respectively, while the sugars content was determined in the hydrolysates using high-performance liquid chromatography). It was expected that the two-step procedure (Fig. 1(1)) would allow for products with lower chemical complexity and higher cellulose content compared to the one-step procedure (Fig. 1(2)).

Table 3 summarizes the composition of the pulps obtained. The use of distinct concentrations of cooking liquor allows to obtain lignocellulosic materials with different chemical complexity (different lignin content). In fact, higher concentration of cooking liquor (aqueous solution of $\mathrm{Na}_{2} \mathrm{CO}_{3}, \mathrm{NaOH}$ and $\mathrm{Na}_{2} \mathrm{~S}$ ) led to products with lower lignin content (Table 3, D2 compared to D3 and D1 compared to D4). Additionally, the hot water extraction together with kraft cooking yielded pulps with a significantly lower hemicelluloses (xylan) content, as expected, and a larger cellulose content (Table 3). Furthermore, when comparing the obtained pulps D2 and D3 to commercially available Eucalyptus bleached pulp $\left(\mathrm{C}_{\mathrm{p}}\right)$, the purity of the former, evaluated by their cellulose content, is higher.

Typically, a higher lignin content is translated into a higher kappa number. However, in the case of the comparison of the D1 and D3 pulps, it is observed that the D3 pulp, although with a higher lignin content, shows a lower kappa number. For hardwood pulps, besides lignin, hexenuronic acid groups formed from xylan during the kraft cooking ${ }^{23}$ also contribute to the kappa number. ${ }^{24}$ The D3 pulp, which has been obtained with a previous hot water extraction of the initial wood sample, presents a substantially lower xylan content (Table 3), and thus less hexenuronic acids. The balance of both contributions (lignin and hexenuronic acids) provides a slightly lower kappa number for the D3 pulp in comparison to the D1 pulp.

\section{Modification of pulps with diverse lignin content and characterization of the obtained materials}

Preparation of dialdehyde lignocellulose by periodate oxidation of pulp. Previously to the oxidation, a mass of $4 \mathrm{~g}$ (dry basis) of Eucalyptus lignocellulosic pulp was mixed with 
Table 2 Kraft cooking experiments

\begin{tabular}{|c|c|c|c|c|c|}
\hline Name & $\begin{array}{l}\text { Liquor-to-wood } \\
\text { ratio }\end{array}$ & $\begin{array}{l}\text { Active alkali charge } \\
(\%)\end{array}$ & Temp. $\left({ }^{\circ} \mathrm{C}\right)$ & $\begin{array}{l}\text { Time at maximum temp. } \\
\text { (min) }\end{array}$ & Kappa number \\
\hline \multicolumn{6}{|c|}{ Hot water extracted Eucalyptus wood chips wastes } \\
\hline D3 & 3.5 & 14 & 160 & 60 & 13.9 \\
\hline \multicolumn{6}{|c|}{ Un-extracted Eucalyptus wood chips wastes } \\
\hline
\end{tabular}

distilled water at $4 \%$ consistency, and the mixture was stirred overnight using a magnetic stirrer, to enable a good disintegration/swelling of the cellulosic fibers.

Highly oxidized lignocellulosic material was produced, as follows. The lignocellulosic pulp suspension was placed in a round flask and diluted with $300 \mathrm{~mL}$ of distilled water. The reaction vessel was covered with aluminium foil to prevent the photo-induced decomposition of periodate and placed in an oil bath. $7.2 \mathrm{~g}$ of $\mathrm{LiCl}$ and $8.2 \mathrm{~g}$ of $\mathrm{NaIO}_{4}$ were then added to initiate the reaction. The reaction mixture, at $\mathrm{pH} 3.0$ (measured at 25 ${ }^{\circ} \mathrm{C}$ ), was stirred with a magnetic stirrer and kept at the desired temperature of $75{ }^{\circ} \mathrm{C}$ for $3 \mathrm{~h}$. Afterwards, the suspension was cooled, and the product was filtered off and washed thoroughly with distilled water to remove iodine-containing compounds. The non-dried dialdehyde lignocellulose (DAC) product was stored in the fridge and used later for the further modifications and aldehyde content determination. Moreover, DAC samples oven-dried at $60{ }^{\circ} \mathrm{C}$ were used for FTIR-ATR measurements.

The aldehyde content of DAC was determined based on the oxime reaction between aldehyde groups and $\mathrm{NH}_{2} \mathrm{OH} \cdot \mathrm{HCl}$, as described in the literature..$^{25}$

Preparation of water-soluble cationic lignocellulose by cationization of DAC. Non-dried DAC ( $0.8 \mathrm{~g}$ on a dry basis) and Girard's reagent T (GT) were added to $80 \mathrm{~mL}$ of distilled water. The $\mathrm{pH}$ of the reaction mixture was adjusted to 4.5 with dilute $\mathrm{HCl}$ and the mixture was stirred for $1 \mathrm{~h}$ at $70{ }^{\circ} \mathrm{C}$ for cationization to occur. After cooling to room temperature, isopropanol was added to precipitate the soluble product (CDAC - cationic dialdehyde lignocellulose). The mixture was centrifuged for $30 \mathrm{~min}$ at $4500 \mathrm{rpm}$, after which, the supernatant was removed. The solid product was washed with a water/isopropanol solution $(1 / 9, v / v)$ and the centrifugation was repeated; these operations were performed several times, until the supernatant showed no GT. Removal of the residual GT was monitored by adding a small amount of $\mathrm{AgNO}_{3}$ to the supernatant. The absence of $\mathrm{AgCl}$ precipitate indicated that the washing was complete. Finally, the cationic product was oven-dried at $60{ }^{\circ} \mathrm{C}$ and then stored in a desiccator. The GT/aldehyde molar ratio was varied from 0.975 to 3.9 , in order to obtain diverse cationization levels in the final products.

The final cationic products were characterized by FTIR and ${ }^{1} \mathrm{H}$ NMR spectroscopy, elemental analysis, hydrodynamic diameter and $\zeta$-potential measurements. FTIR-ATR spectra were obtained on a Bruker Tensor 27 spectrometer, using 128 scans and a resolution of $4 \mathrm{~cm}^{-1}$, in the range of $600-4000 \mathrm{~cm}^{-1} \cdot{ }^{1} \mathrm{H}$ NMR spectra of the cationic lignocellulose samples dissolved in $\mathrm{D}_{2} \mathrm{O}\left(10 \mathrm{mg} \mathrm{mL}{ }^{-1}\right)$ were collected in a Bruker Avance III 400 MHz NMR spectrometer using a Bruker standard pulse program. $\mathrm{C}, \mathrm{H}$ and $\mathrm{N}$ elemental analyses were performed using an element analyzer EA 1108 CHNS-O from Fisons. 2,5-Bis(5tert-butyl-benzoxazol-2-yl)thiophene was used as standard. The nitrogen content was used to obtain the corresponding degree of cationization of lignocelluloses.

Hydrodynamic diameter and zeta potential of the cationic lignocellulose materials were determined by dynamic light scattering and electrophoretic light scattering, respectively, in

Table 3 Raw materials used for synthesis of dialdehyde lignocellulose and results of their characterization ${ }^{a}$

\begin{tabular}{|c|c|c|c|c|}
\hline Name & Kappa number & $\begin{array}{l}\text { Cellulose content } \\
\text { (wt\%) }\end{array}$ & $\begin{array}{l}\text { Xylan content } \\
\text { (wt\%) }\end{array}$ & $\begin{array}{l}\text { Total lignin } \\
\text { content (wt } \%)\end{array}$ \\
\hline \multicolumn{5}{|c|}{ Commercially available Eucalyptus bleached kraft pulp ${ }^{b}$} \\
\hline $\mathrm{C}_{\mathrm{p}}$ & - & 85 & 14 & $<0.1$ \\
\hline \multicolumn{5}{|c|}{ Eucalyptus wood wastes pulps ${ }^{c}$} \\
\hline D2 & 10.2 & 90.2 & 7.3 & 1.9 \\
\hline D3 & 13.9 & 89.6 & 7.2 & 2.8 \\
\hline D1 & 16.1 & 76.7 & 17.5 & 2.2 \\
\hline D4 & 26.7 & 71.6 & 18.3 & 4.4 \\
\hline
\end{tabular}

${ }^{a} \mathrm{C}_{\mathrm{p}}$ : commercially available bleached pulp; D2 and D3: pulps obtained by kraft cooking with previous hot water extraction of the wood wastes; D1 and D4: pulps obtained by kraft cooking. ${ }^{b}$ Values taken from the literature. ${ }^{22} c$ Xylan content does not include substituent acid groups. 
a Zetasizer NanoZS, ZEN3600, from Malvern Instruments, with backscatter detection at a $173^{\circ}$ angle and temperature set up to $25{ }^{\circ} \mathrm{C}$. For the hydrodynamic diameter measurements, a stock solution of $0.2 \mathrm{~g} \mathrm{~L}^{-1}$ in Milli-Q water was prepared, stirred during $1 \mathrm{~h}$, and then sonicated during $2 \mathrm{~min}$. After that process, the cationic lignocellulose sample solution was passed through a $0.45 \mu \mathrm{m}$ syringe filter directly to the glass cell. Using automatic measurements mode, with at least 5 repetitions of the measurement, the average hydrodynamic diameter $(\mathrm{nm})$ of the cationic lignocellulose samples in solution ( $Z$-average diameter) and the PDI (polydispersity index) of the hydrodynamic diameter distribution were obtained. Zeta potential measurements were performed using a $0.1 \mathrm{~g} \mathrm{~L}^{-1}$ stock solution prepared in Milli-Q water. With a syringe, $1 \mathrm{~mL}$ of sample for analysis was carefully injected directly into the disposable plastic capillary cell and triplicate measurements were conducted.

\section{Evaluation of performance in color removal}

Selected dyes and dyes characterization. In the present study, two dyes were selected for the preparation of model colored effluents: Basic Green 1 (Alfa Aesar), and Duasyn Direct Red 8BLP (Feldkirch Inc.). Their characterization, including ultraviolet/visible spectra, $\mathrm{pH}$ and conductivity of aqueous solutions, can be found elsewhere. ${ }^{25}$ These two dyes were chosen since they are examples, respectively, of a basic (cationic) dye and of a direct (anionic) dye, commonly employed in the textile and cosmetic industry.

Coagulation-flocculation experiments. The jar-test was applied in order to evaluate the flocculation performance of the water-soluble cationic lignocelluloses with diverse lignin contents that possessed the highest and the lowest degree of cationization. The cationic sample solution for the flocculation test was prepared by dissolving the cationic polymer, at $0.04 \mathrm{wt} \%$ concentration, in distilled water, and stirring at $500 \mathrm{rpm}$ for $30 \mathrm{~min}$. The model effluent was prepared by adding a certain amount of dye (the amount for each dye was the one leading to saturation and depended on the type of dye) to distilled water and stirring at $500 \mathrm{rpm}$. For the flocculation experiment, $150 \mathrm{~mL}$ of the dye solution was placed in a beaker, and, if required, the $\mathrm{pH}$ adjusted to the target value by adding $\mathrm{NaOH} 10 \%$ or $\mathrm{H}_{2} \mathrm{SO}_{4} 10 \%$. A suitable dosage of flocculant was then added dropwise, while mixing slowly during $20 \mathrm{~s}$; for most of the experiments, bentonite (whose characteristics are summarized in Table 4) was also added before the cationic flocculant addition. Supernatant samples of approximately

Table 4 Characteristics of the bentonite in aqueous suspension ${ }^{a}$

\begin{tabular}{lllll}
\hline $\mathrm{pH}$ & $\begin{array}{l}\zeta \text {-Potential } \\
(\mathrm{mV})\end{array}$ & $\begin{array}{l}d(0.5) \\
(\mu \mathrm{m})\end{array}$ & $\begin{array}{l}d(0.9) \\
(\mu \mathrm{m})\end{array}$ & $\begin{array}{l}D[3.2] \\
(\mu \mathrm{m})\end{array}$ \\
\hline 9.6 & $-43 \pm 1$ & 2.3 & 3.4 & 2.1
\end{tabular}

${ }^{a} d(0.5)$ - median of the particle size distribution; $d(0.9)-90 \%$ undersize percentile diameter of the particle size distribution; $D[3.2]$ - surface weighted mean.
$2 \mathrm{~mL}$ were pipetted from the center of the beaker, for the determination of color removal over time $(1 \mathrm{~min}, 30 \mathrm{~min}, 1 \mathrm{~h}$, and $24 \mathrm{~h}$ ). The decoloration was calculated by measuring turbidity of the supernatant, assessed with at least three repetitions, using a Photometer MD600 (Lovibond, UK). Comparison was made with the cationic products obtained from Eucalyptus bleached pulp and with a commercial cationic polyacrylamide (cPAM).

\section{Results and discussion}

\section{Synthesis and characterization of dialdehyde lignocelluloses and cationic modified lignocelluloses}

Modification of cellulosic pulps with diverse cellulose purity (from wood wastes: D1-D4, and bleached pulp: $\mathrm{C}_{\mathrm{p}}$ ) (Table 3), was conducted in a two-step procedure: DAC was first synthesized by oxidation of pulp with sodium periodate, and then the resultant material underwent the reaction with Girard's reagent $\mathrm{T}$, yielding the cationic derivative (Fig. 2). It is important to mention here that having been used as raw material for the modification pulps with high chemical heterogeneity (namely with a relatively high lignin content), the influence of that heterogeneity in the final properties of the obtained products was evaluated. In other studies, birch bleached cellulose containing about $25 \%$ of hemicelluloses, ${ }^{6}$ as well as alkali-extracted Eucalyptus bleached pulp with $6 \%$ of xylan, ${ }^{25}$ have been already cationized using the described sequence of periodate oxidationGT modification. However, to the best of our knowledge never before this two-step reaction was applied and evaluated to modify pulps with higher chemical complexity, namely lignin content. This is an important factor, since the characteristics and properties of the original cellulose source such as, its chemical composition, the molecular weight and size of the polysaccharide molecules, may alter not only the characteristics but also the performance of the final cationic product in a targeted application. Furthermore, it may happen that with the increase in lignin content together with the decrease of uniformity in the distribution of the molecular size of the polysaccharides, chemical modifications may be more difficult and adjustments may be required.

The desired, high functionality through the introduction of positively charged quaternary ammonium groups spread among the polymeric backbone, would ideally allow to obtain water soluble products. However, the key step in the production of cellulose-based PELs through the selected route is periodate oxidation that allows to introduce two highly reactive aldehyde

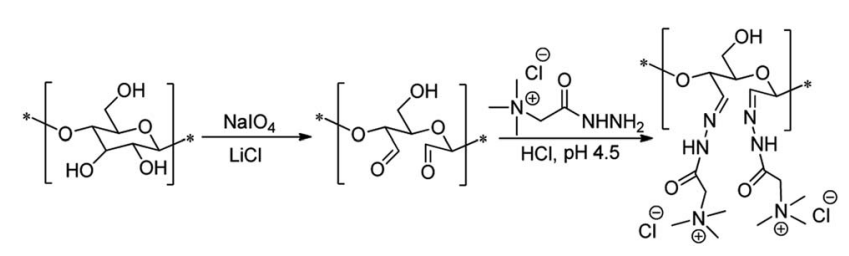

Fig. 2 Reaction scheme showing the two-step reaction used to produce cationic lignocellulose. 
groups per AGU unit. The overall results of periodate oxidation performed on pulps with diverse chemical heterogeneity (Eucalyptus bleached pulp, kraft pulps with different kappa numbers and produced with or without previous hot water extraction of the wood wastes) showed that chemical composition of the initial materials, within the studied range, does not have a significant influence on the obtained oxidized products when applying optimized modification conditions with an excess of periodate $\left(75^{\circ} \mathrm{C}, 3 \mathrm{~h}, 9.6(\mathrm{mmol}) \mathrm{NaIO}_{4}\right.$ per $(\mathrm{g})$ pulp and $1.8 \mathrm{LiCl} /$ pulp weight ratio) (Fig. 3). Furthermore, the produced $\mathrm{DAC}_{\mathrm{p}}$ from bleached pulp possessed $c a .10 .17 \mathrm{mmol}$ $\mathrm{g}^{-1}$ of aldehyde groups which corresponds to a degree of substitution of $c a$. 1.64, while, when applying the oxidation procedure for a set of more heterogeneous lignocellulosic materials obtained by kraft cooking of wood wastes with and without previous hot water extraction, similar degrees of oxidation were reached. Thus, the results of periodate oxidation show that using more complex raw materials, with typically lower cellulose content and with higher content of lignin, has no significant influence on the obtained dialdehyde lignocellulose derivatives. Using pulps prepared by hot water pretreatment followed by soft cooking (series of $\mathrm{DAC}_{\text {waq }}$ samples; D2, D3) or pulps prepared applying only soft cooking $\left(\mathrm{DAC}_{\mathrm{w}}\right.$ samples; D1, D4) did not provide any consistent difference on the obtained products, enabling to obtain $\mathrm{DAC}_{\mathrm{waq}}$ with an aldehyde content from 10.15 to $10.47 \mathrm{mmol} \mathrm{g}^{-1}$ and $\mathrm{DAC}_{\mathrm{w}}$ with 10.35-10.40 mmol g ${ }^{-1}$ of aldehyde content (Fig. 3). These correspond to degrees of substitution of hydroxyl groups by aldehyde groups in the polysaccharides probably higher than 1.5. Note that in the periodate oxidation process, lignin can also be oxidized (into ortho- and para-quinones), ${ }^{26}$ which could influence the determined aldehyde groups content value. However, considering the lignin content present in the initial lignocellulosic raw materials, of less than $5 \%$ (Table 3 ) and the preference for a selective oxidation of the polysaccharide's backbone, the lignin oxidation should have a minor contribution to the final degree of oxidation/substitution achieved in the DAC materials.

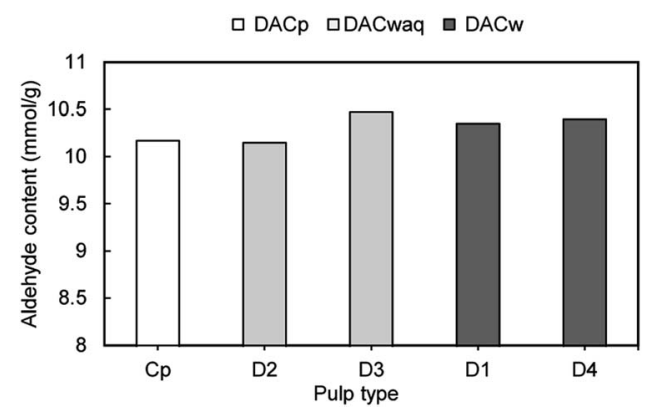

Fig. 3 Influence of different lignin content of the raw materials on the aldehyde groups content during the periodate oxidation. The reaction conditions were kept constant in all experiments at $75^{\circ} \mathrm{C}$ and $3 \mathrm{~h}$. $\mathrm{DAC}_{\mathrm{p}}$ corresponds to dialdehyde cellulose obtained from bleached pulp, $D A C_{\text {waq }}$ to dialdehyde lignocellulose obtained from pulp prepared by hot water extraction/kraft cooking, and $\mathrm{DAC}_{\mathrm{w}}$ corresponds to dialdehyde lignocellulose obtained from kraft pulp.
The highly oxidized dialdehyde lignocellulose derivatives were then cationized in order to obtain bio-PELs. The reaction occurred between the aldehyde functionalities and the cationic Girard's reagent T ((2-hydrazinyl-2-oxoethyl)-trimethylazanium chloride) in an acidic medium ( $\mathrm{pH} 4.5)$. The introduction of positively charged quaternary ammonium groups followed the path described in Fig. 2.

The obtained products were characterized and further studied as flocculants with model effluents. It is more likely that if the aldehyde content of DAC is higher and a large excess of GT is used, a higher extent of derivatisation of aldehyde groups in DAC to imine groups, is going to be achieved, and a higher cationic content will be obtained at the end. The variation of the cationization reaction parameter, the GT/aldehyde molar ratio, was used to obtain natural-based polyelectrolytes with different degrees of cationization, cationicity values ranging from 2.84 to $3.74 \mathrm{mmol} \mathrm{g}^{-1}$ having been obtained (Table 5).

As it was expected and in agreement with results previously published with other cellulosic substrates ${ }^{6,7,25,27}$ typically the increase of the GT/aldehyde molar ratio yields higher cationicity. Moreover, for the tested pulp with the highest lignin content and with a GT/aldehyde ratio of 0.975 (Table 5, sample $\mathrm{CDAC}_{\mathrm{D} 4} \mathrm{C}$ ), a still high level of cationization was achieved $\left(2.84 \mathrm{mmol} \mathrm{g}^{-1}\right)$. In general, the cationicity index values were lower for the polyelectrolytes obtained from the lignocellulosic pulps in comparison to those produced from the bleached cellulosic pulp. These results should reflect a higher reactivity of the initial raw material in the latter case, almost only composed by polysaccharides and without lignin. Considering the importance of a high content of ionic groups to obtain a sufficient charge of the cellulose-based material and an adequate water solubility, the cellulosic derivatives obtained with the highest and the lowest GT/aldehyde molar ratio (that is, products with the highest and the lowest charge density) from each tested pulp were evaluated as natural-based flocculation agents for dyes removal.

The presence of aldehyde groups at the $\mathrm{C} 2-\mathrm{C} 3$ positions in the obtained dialdehyde products was confirmed by FTIR spectroscopy (Fig. 4). Several differences between the cellulosic pulps starting material and the prepared DAC samples were observed. However, all obtained dialdehyde cellulose products were in agreement with the presence of aldehyde groups and showed similar fingerprints. Moreover, the obtained DAC spectra also agreed with literature. ${ }^{6,11,28}$ In the DAC spectrum, due to the $\mathrm{C}=\mathrm{O}$ stretching of aldehyde groups, a new band, comparing to the spectrum of the initial cellulosic material, appeared at $c a .1730 \mathrm{~cm}^{-1}$. Furthermore, several differences in the region between 1000 and $1200 \mathrm{~cm}^{-1}$ were also noted. In particular, the characteristic band of cellulose at $1162 \mathrm{~cm}^{-1}$, due to the asymmetric $\mathrm{C}-\mathrm{O}-\mathrm{C}$ stretching of the glycosidic bond, is not well defined in the DAC spectra. Additionally, the characteristic $\mathrm{C} 1-\mathrm{H}$ bending band at $897 \mathrm{~cm}^{-1}$ was shifted to $c a$. $880 \mathrm{~cm}^{-1}$. These new features confirmed the ring opening and oxidation of $\mathrm{OH}$ groups at $\mathrm{C} 2-\mathrm{C} 3$ positions.

Finally, the quaternary ammonium derivatisation of the DAC adducts was performed (Fig. 2) and the products characterized by elemental analysis, ${ }^{1} \mathrm{H}$ NMR and FTIR spectroscopy, size and 
Table 5 Reaction conditions used for synthesis of cationic bio-PELs and characterization of final products ${ }^{a}$

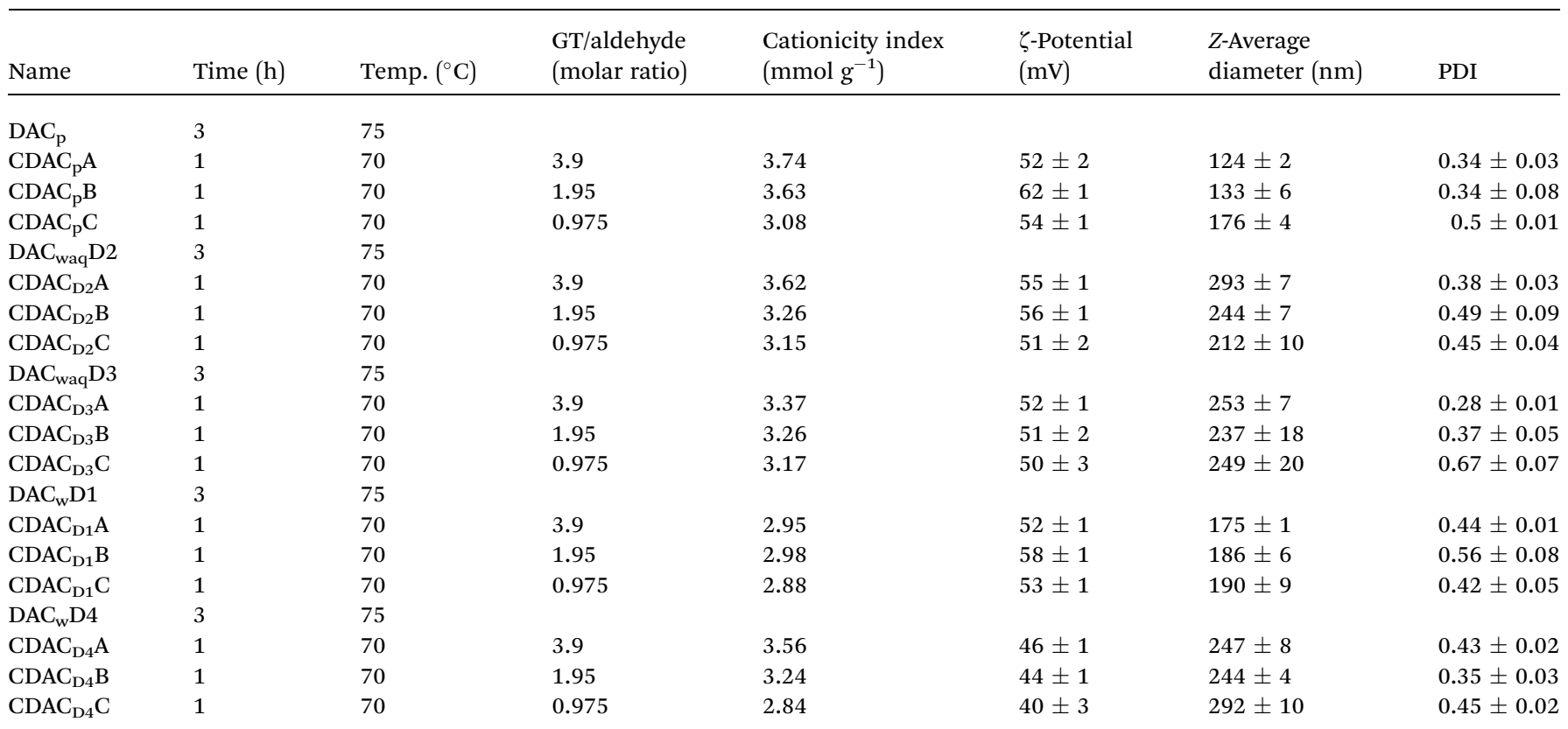

${ }^{a}$ Cationicity determined as the amount of alkylammonium groups ( $\mathrm{mmol}$ ) per $\mathrm{g}$ (dry weight) of cationic lignocellulose sample; PDI - polydispersity index of the hydrodynamic diameter distribution; dialdehyde lignocellulose from: $\mathrm{DAC}_{\mathrm{waq}} \mathrm{D} 2$, from wood wastes pulp with kappa no. 10.2 , $\mathrm{DAC}_{\mathrm{waq}} \mathrm{D} 3$, from wood wastes pulp with kappa no. 13.9, $\mathrm{DAC} \mathrm{C}_{\mathrm{w}} \mathrm{D}$, from wood wastes pulp with kappa no. 16.1, DAC $\mathrm{w}$, , from wood wastes pulp with kappa no. 26.7.

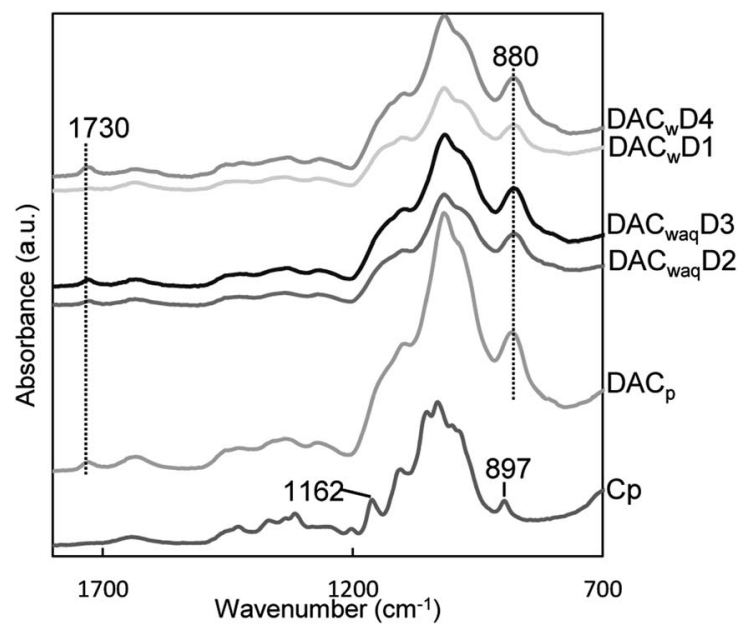

Fig. 4 FTIR spectra of bleached cellulosic pulp $\left(C_{p}\right)$, and dialdehyde cellulose samples produced (at $75{ }^{\circ} \mathrm{C}$ during $3 \mathrm{~h}$, with a $9.6 \mathrm{NalO}_{4}$ / cellulosic pulp ratio) from different raw materials: from bleached cellulosic pulp, from Eucalyptus wood chips wastes subjected to mild cooking together with hot water extraction pre-treatment (kappa numbers of 10.2 and 13.9), and cooking without any hot water pretreatment (kappa numbers of 16.1 and 26.7), i.e., $\mathrm{DAC}_{\mathrm{p}}, \mathrm{DAC}_{\text {waq }} \mathrm{D} 2$, $\mathrm{DAC}_{w a q} \mathrm{D} 3, \mathrm{DAC}_{\mathrm{w}} \mathrm{D} 1$ and $\mathrm{DAC} \mathrm{w}_{\mathrm{w}} \mathrm{D} 4$, respectively.

zeta potential measurements. The ${ }^{1} \mathrm{H}$ NMR spectra of the watersoluble quaternary ammonium cellulosic derivatives produced from DACs of different origin (samples $\mathrm{CDAC}_{\mathrm{p}} \mathrm{A}, \mathrm{CDAC}_{\mathrm{D} 2} \mathrm{~A}$ and $\left.\mathrm{CDAC}_{\mathrm{D} 4} \mathrm{~A}\right)$ are presented in Fig. 5. The presence of highintensity signals at $3.23-3.29 \mathrm{ppm}$, can be attributed to

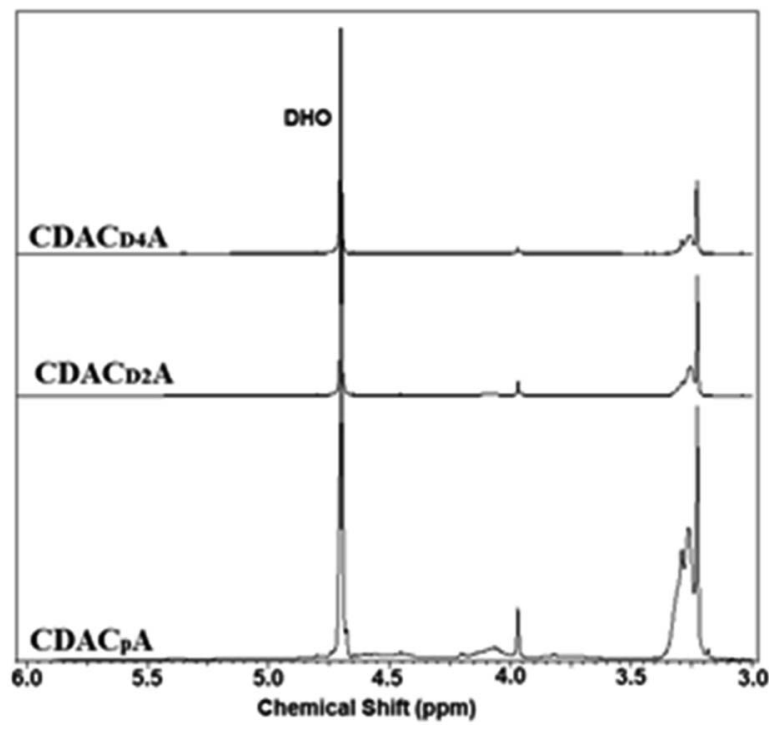

Fig. $5{ }^{1} \mathrm{H}$ NMR spectra of cationic cellulosic derivatives: $C D A C_{p} A$, $\mathrm{CDAC}_{\mathrm{D} 2} \mathrm{~A}$ and $\mathrm{CDAC}_{\mathrm{D} 4} \mathrm{~A}$.

methyl protons $\left(\mathrm{H}_{3} \mathrm{C}\right)$ of alkylammonium moieties, protons linked to the carbon between the alkylammonium group and the $\mathrm{C}=\mathrm{O}(\mathrm{NH})$ amide group, and protons linked to the carbon in the $\mathrm{HC}=\mathrm{N}-$ imine bond. The intensity of the signals at 3.23$3.29 \mathrm{ppm}$ typically increased with the increase of the degree of quaternary ammonium groups substitution (Fig. 5). Fig. 6 shows the FTIR spectra of cationic celluloses, with several new bands not present in the spectrum of dialdehyde cellulose or 


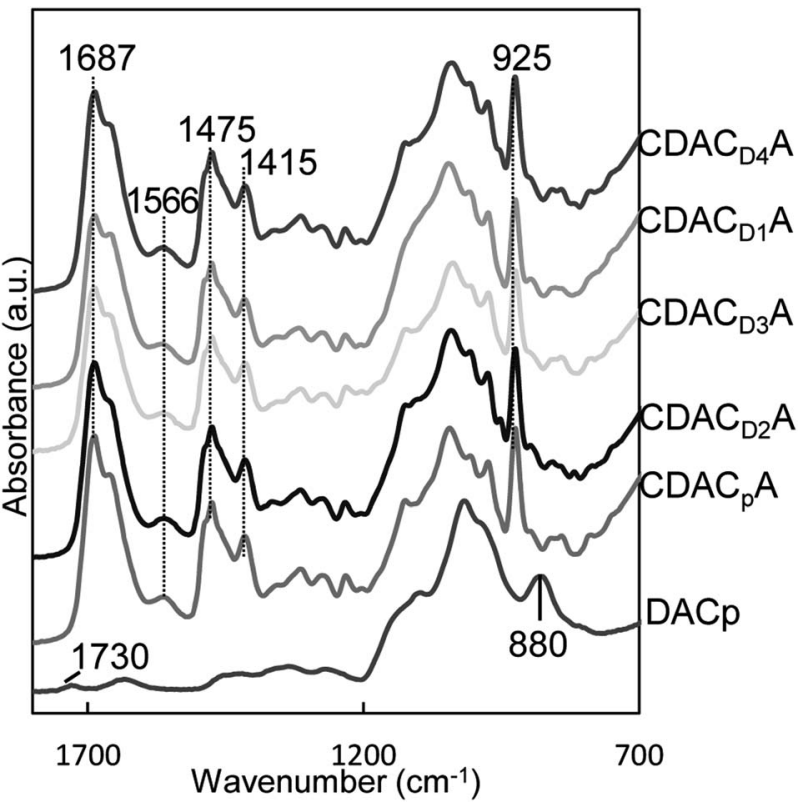

Fig. 6 FTIR spectra of dialdehyde cellulose and cationic cellulosic materials from different DAC sources. All presented CDACs were obtained while performing cationization with a 3.9 GT/aldehyde molar ratio at $70^{\circ} \mathrm{C}$ during $1 \mathrm{~h}$.

initial cellulosic pulp. A very intense band at $1687 \mathrm{~cm}^{-1}$, which corresponds to the carbonyl stretching of amide group (amide I band), accompanied by a less intense band at $1566 \mathrm{~cm}^{-1}$ due to the carbon-nitrogen stretching in the amide group (amide II band) were observed. New bands from the asymmetric and symmetric bending of methyl groups also appeared at 1475 and $1415 \mathrm{~cm}^{-1}$. The sharp band at $925 \mathrm{~cm}^{-1}$ was due to the asymmetric $\mathrm{NC}_{4}$ stretching of the alkylammonium groups. Therefore, ${ }^{1} \mathrm{H}$ NMR and FTIR spectroscopy gave clear evidence that cationization of lignocellulosic materials with diverse chemical composition, through the formation of imine bonds by the condensation reaction of DAC with GT reagent, occurred.

Zeta potential of cellulose-based, water-soluble, cationic PELs was between $40 \mathrm{mV}$ and $62 \mathrm{mV}$, what confirmed the success of the cationization process and the production of positively charged molecules. Moreover, by increasing the excess of Girard's reagent $\mathrm{T}$ in the modification procedure, typically bio-PELs with higher cationicity index (and degree of substitution) and thus higher zeta potential, can be produced. However, even if the cationicity index $\left(2.88-3.62 \mathrm{mmol} \mathrm{g}^{-1}\right)$ differed a lot between CDACs obtained from initial wood pulps with kappa number between 10.2 and 16.1, this did not show a very high influence in the zeta potential results that were between $50 \pm 3 \mathrm{mV}$ and $58 \pm 1 \mathrm{mV}$. Moreover, in the series $\mathrm{CDAC}_{\mathrm{D} 4}$, obtained from the initial material with the highest kappa number (26.7), the measured zeta potential results were lower, in the range of $40 \pm 3 \mathrm{mV}$ to $46 \pm 1 \mathrm{mV}$, which can be attributed to the negative impact of a high fraction of unmodified lignin that did not undergo cationization. It was noticeable a tendency relating hydrodynamic diameter and the degree of substitution by cationic groups, in materials obtained from initial wood pulps with hot water extraction, where with the increase in degree of substitution, hydrodynamic diameter also increases, as the result of charges repulsion. For the biopolymers obtained from more heterogeneous raw materials this trend is not notorious. Additionally, when bleached fibers were used as raw materials the hydrodynamic diameter of CDACs obtained is lower, probably due to cellulose degradation during bleaching. Moreover, the high average hydrodynamic diameter, in the range of $124 \pm 2$ to $293 \pm 7 \mathrm{~nm}$, of the modified cationic products obtained, demonstrated that during the first step of modification, when using periodate oxidation, the cellulose backbone was not destroyed till individual molecules, the reaction allowing to obtain dialdehyde cellulose, which was afterwards submitted to further modification with alkylammonium compound leading to a polydisperse branched type of cellulose with positive charges (polydispersity index from $0.28-$ 0.67). Overall, all the cationically modified DACs obtained from wood pulps with different kappa numbers, showed to be water soluble at room temperature, and thus can be strong candidates to be applied as natural-based flocculants in wastewater treatment.

\section{Decoloration studies (dye removal)}

The results of the decoloration tests, using developed PELs with the highest and the lowest substitution degree by cationic units, for the two tested model effluents will be presented here and discussed individually for each dye. Even if it is known that most decoloration treatments rely on adsorption, ${ }^{29}$ in the present study good results were attained with the strategy developed based on the new bio-PELs.

The most important when decoloring dye-contaminated effluents is to take into account the dyes chemical structures, since some of the dyes have positively charged organic chromophores while others have negatively charged ones. Two dyes were selected to evaluate the performance of the new obtained flocculants: Basic Green 1 and Duasyn Direct Red. Their structure is shown in Fig. 7. Basic Green 1 is an example of a basic (cationic) dye with a triarylmethane chromophore and Duasyn Direct Red is an example of a direct dye with nitrogen-nitrogen azo bonds and sulfonate groups, the latter conferring a negative charge to the chromophore (anionic). Furthermore, changing $\mathrm{pH}$ can promote ionization of certain groups in the dye structure letting to obtain a charge variation with the $\mathrm{pH}$. The zeta potential values, as a function of $\mathrm{pH}$, for the two tested dyes, are presented in Fig. 8. The initial charge for each dye was highlighted. As it was expected the charge of the tested dyes showed

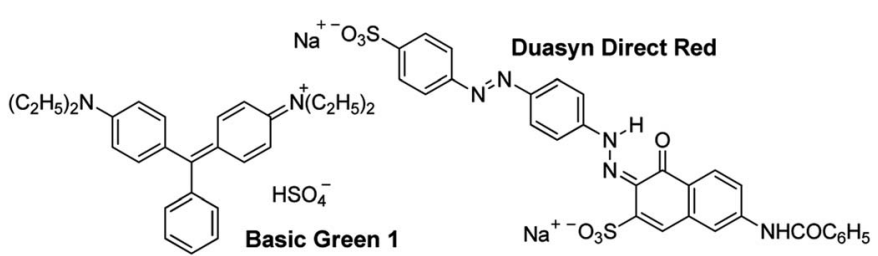

Fig. 7 Chemical structure of Basic Green 1 and Duasyn Direct Red dyes. 


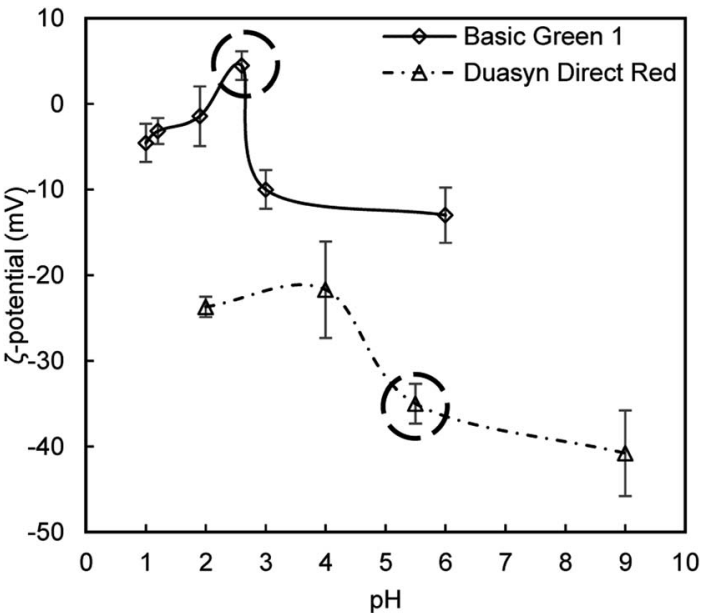

Fig. 8 Zeta potential values for two tested model effluents as a function of $\mathrm{pH}$. The initial zeta potential of the dye without $\mathrm{pH}$ adjustment is highlighted.

to be $\mathrm{pH}$ dependent. Different performances for the tested flocculants are then expected to be observed with the change of $\mathrm{pH}$.

Basic Green 1. The results of the turbidity reduction obtained for the Basic Green 1 model effluent, while using cationic cellulose-based flocculation agents produced from Eucalyptus raw materials of different cellulose, lignin and hemicellulose contents, are summarized in Fig. 10-12. The preliminary tests were carried out with $\mathrm{CDAC}_{\mathrm{p}} \mathrm{A}$ (cationic cellulose-based PEL obtained from bleached pulp) and CPAM (synthetic PEL of similar charge) (see Fig. 9). In the performed trials different $\mathrm{pH}$ levels were used, to evaluate the influence of $\mathrm{pH}$ dependency of the charge of the tested dye, as a factor for system destabilization and flocculation performance. In the preliminary tests, both acidic and alkaline $\mathrm{pH}$ were considered ( $\mathrm{pH} 1.6$ and 10.6).

Fig. 9 shows the color removal results at two different pHs (1.6 and 10.6) for $4.0 \mathrm{mg} \mathrm{L}^{-1}$ of CDAC $_{\mathrm{p}} \mathrm{A}$ and synthetic cPAM, in single systems. The decoloration results were always better at acidic conditions for both cellulose-based and synthetic

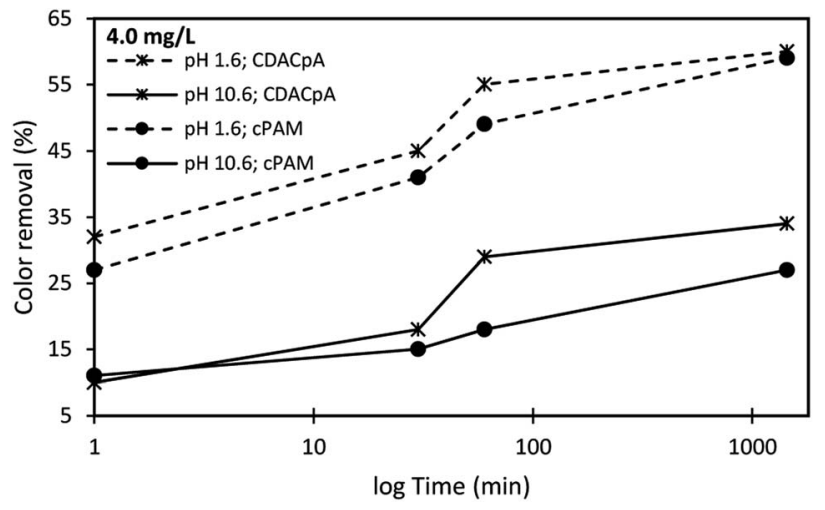

Fig. 9 Basic Green 1 color removal using the flocculation agent alone (4.0 $\mathrm{mg} \mathrm{L}^{-1}$ of synthetic cPAM or cellulose-based $\mathrm{CDAC}_{\mathrm{p}} \mathrm{A}$ ) at two different $\mathrm{pH}$ levels, 1.6 and 10.6. flocculation agents, with a maximum removal around $60 \%$ for a $24 \mathrm{~h}$ period. At $\mathrm{pH} 1.6, \mathrm{CDAC}_{\mathrm{p}} \mathrm{A}$ was more effective in the Basic Green 1 removal in the first hour of the treatment letting to remove $45 \%$ (after $30 \mathrm{~min}$ ) and $55 \%$ (after $1 \mathrm{~h}$ ), while cPAM removed $41 \%$ and $49 \%$, respectively, after $30 \mathrm{~min}$ and $1 \mathrm{~h}$ of treatment. However, for a $24 \mathrm{~h}$ period of settling it was possible to obtain similar, up to $60 \%$ of decoloration, for both synthetic and natural-based flocculants. For alkaline conditions $(\mathrm{pH}$ 10.6), even if the color removals obtained with $\operatorname{CDAC}_{\mathrm{p}} \mathrm{A}$ and cPAM were poorer, the $\mathrm{CDAC}_{\mathrm{p}} \mathrm{A}$ performed better $\left(\mathrm{CDAC}_{\mathrm{p}} \mathrm{A}\right.$ removed $34 \%$ of dye after $24 \mathrm{~h}$ while cPAM removed only $27 \%$ ).

Basic Green 1 color removal was also tested in dual system with bentonite. Fig. 10-12 show the results obtained at $\mathrm{pH}$ 1.6, 3.0 (close to the model effluent initial $\mathrm{pH}^{25}$ ) and 10.6, while using two different concentrations of flocculation agent: $1.33 \mathrm{mg} \mathrm{L}^{-1}$ (procedure A) or $4.0 \mathrm{mg} \mathrm{L}^{-1}$ (procedure $\mathrm{B}$ ), and $0.14 \mathrm{wt} \%$ of bentonite.

In the presented cases (except in a few cases with some of the CDACs at pH 3.0 and 10.6), better color removal after $24 \mathrm{~h}$ of treatment, was obtained while using dual system compared to procedure using only bentonite, at the same $\mathrm{pH}$ (see Fig. 13). Furthermore, in dual systems, results obtained with naturalbased flocculants were very similar to the ones obtained with the synthetic reference cPAM. Initially, bentonite destabilizes
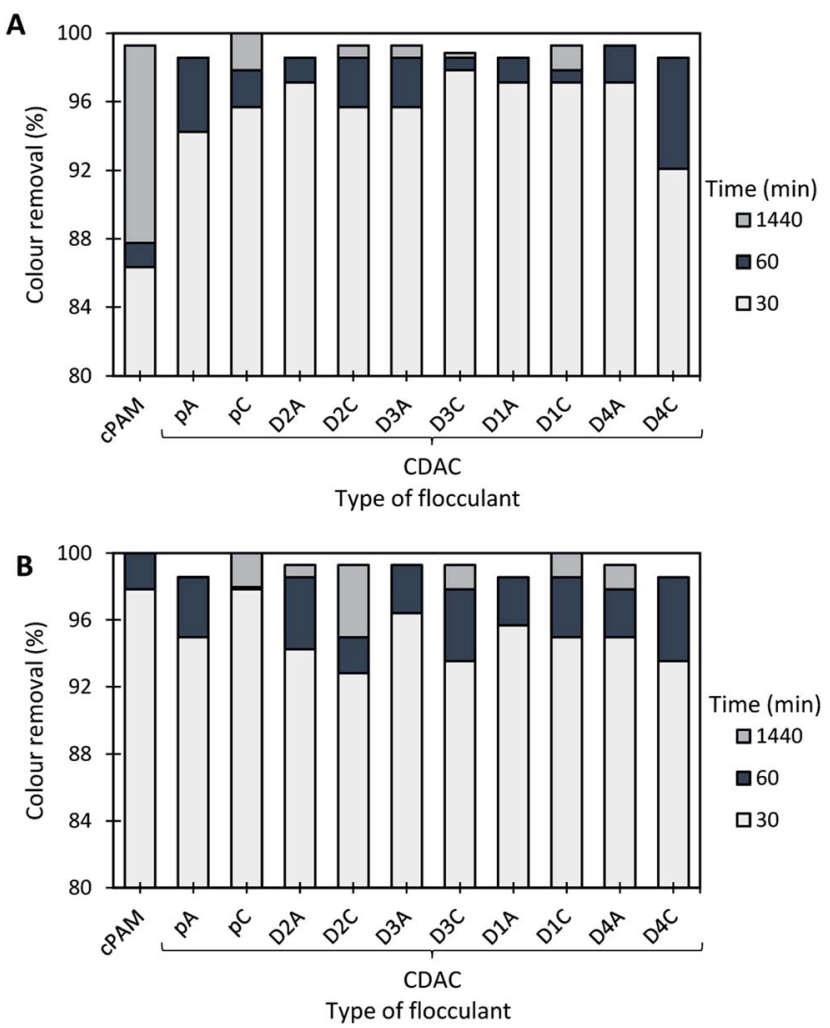

Fig. 10 Basic Green 1 color removal with time, using cellulose-based flocculation agents from different sources in dual system with bentonite at $\mathrm{pH}$ 1.6. Procedure $\mathrm{A}: 0.14 \mathrm{wt} \%$ of bentonite followed by $1.33 \mathrm{mg} \mathrm{L}^{-1}$ of flocculant. Procedure B: $0.14 \mathrm{wt} \%$ of bentonite and $4.0 \mathrm{mg} \mathrm{L}^{-1}$ of flocculant. Cationic synthetic PAM in dual system with bentonite was used as reference. 

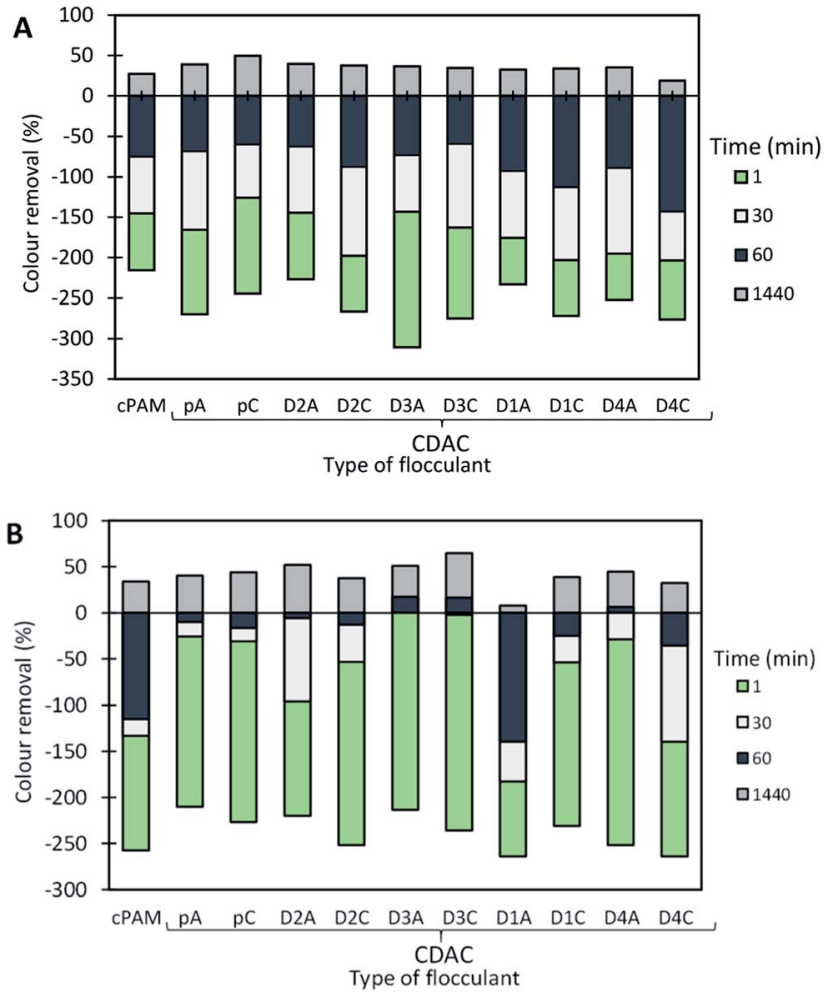

Fig. 11 Basic Green 1 color removal with time, using cellulose-based flocculation agents from different sources in dual system with bentonite at $\mathrm{pH}$ 3.0. Procedure A: 0.14 wt\% of bentonite followed by $1.33 \mathrm{mg} \mathrm{L}^{-1}$ of flocculant. Procedure B: $0.14 \mathrm{wt} \%$ of bentonite and $4.0 \mathrm{mg} \mathrm{L}^{-1}$ of flocculant. Cationic synthetic PAM in dual system with bentonite was used as reference.

the dye, and the turbidity of the system may increase (see Fig. 11 and 12 for $\mathrm{pH} 3.0$ and 10.6), whereas the addition of polymer allows for faster, more effective flocculation due to bridging mechanisms and then to rapid settling. In all the tested procedures, for different $\mathrm{pH}$ levels, the underlying mechanism must be the same. However, bentonite itself at acidic pH levels tends to have slightly positive surface charge,$^{30}$ at $\mathrm{pH} 8.0$ the surface charges reach equilibrium between positive and negative charges, and at more alkaline conditions it tends to be negatively charged. This influences the color removal results for the tested procedures, as shown in Fig. 10-12, making removal very effective at $\mathrm{pH} 1.6$ and less effective at $\mathrm{pH} 3.0$ and 10.6.

The most effective removal of Basic Green 1 was obtained at $\mathrm{pH}$ 1.6, preferentially at lower dosage of flocculant (procedure A with $0.14 \mathrm{wt} \%$ of bentonite followed by $1.33 \mathrm{mg} \mathrm{L}^{-1}$ of flocculant). However, in all the performed tests at $\mathrm{pH}$ 1.6, the decoloration results were quite high, and flocculation occurred rapidly, which must be related to the lower stability of the dye for this $\mathrm{pH}$. The used cationic CPAM showed also to have a high efficiency at $\mathrm{pH}$ 1.6. In general, bio-polymers obtained from pulp with high lignin content, such as $\mathrm{CDAC}_{\mathrm{D} 4} \mathrm{~A}$, showed to work very well, and be very effective in the decoloration of Basic Green 1 at $\mathrm{pH}$ 1.6. One can conclude that cationic cellulosebased flocculants work well for this purpose independently of the raw material used in the modification procedure and final
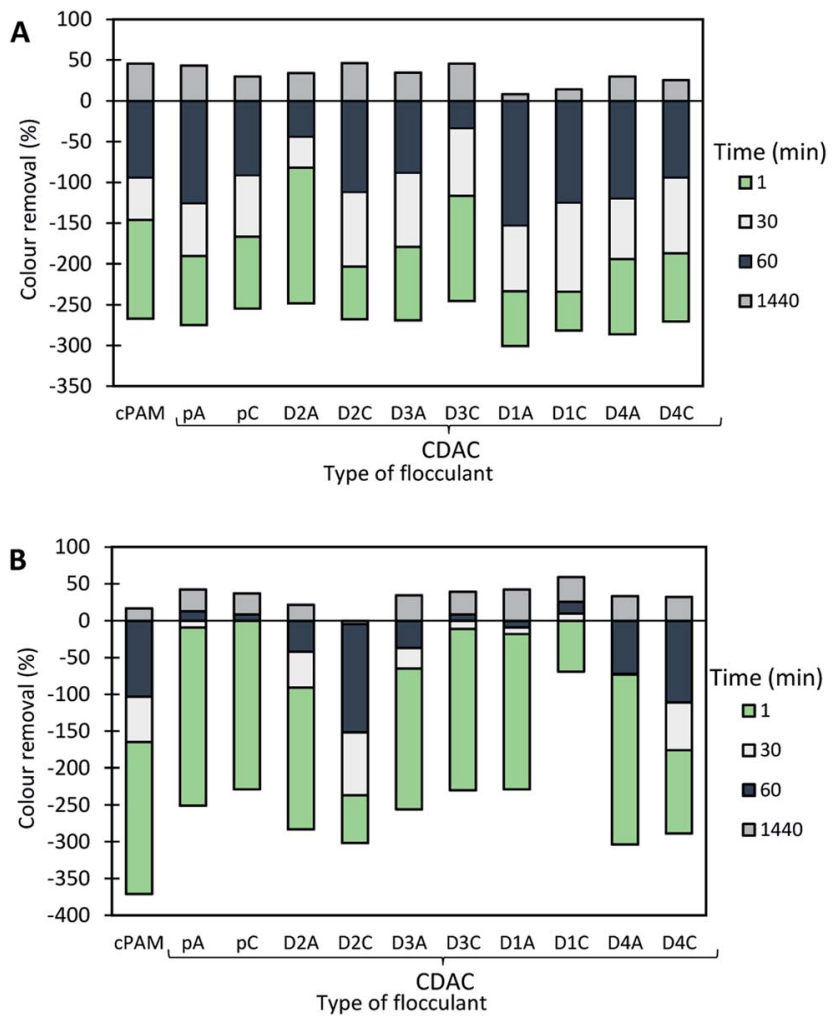

Fig. 12 Basic Green 1 color removal with time, using cellulose-based flocculation agents from different sources in dual system with bentonite at $\mathrm{pH} 10.6$. Procedure A: $0.14 \mathrm{wt} \%$ of bentonite followed by $1.33 \mathrm{mg} \mathrm{L}^{-1}$ of flocculant. Procedure B: $0.14 \mathrm{wt} \%$ of bentonite and $4.0 \mathrm{mg} \mathrm{L}^{-1}$ of flocculant. Cationic synthetic PAM in dual system with bentonite was used as reference.

product characteristics. For the two higher pHs (3.0 and 10.6) the cationic lignocelluloses obtained from the more heterogeneous raw material $\left(\mathrm{CDAC}_{\mathrm{D} 4} \mathrm{~A}\right.$ and $\left.\mathrm{CDAC}_{\mathrm{D} 4} \mathrm{C}\right)$ showed a performance quite similar to the one of the other CDACs.

Duasyn Direct Red. Color removal results obtained for the Duasyn Direct Red model effluent, using cationic cellulosebased flocculation agents obtained from Eucalyptus raw materials of different cellulose and lignin contents, are summarized

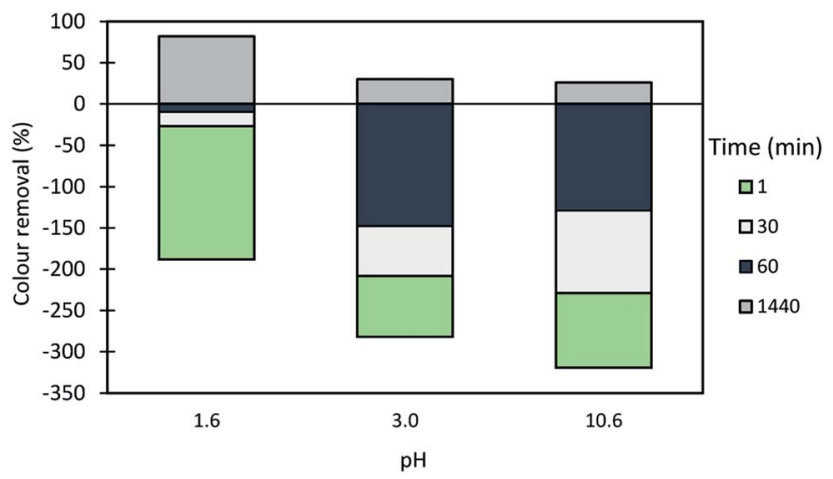

Fig. 13 Basic Green 1 color removal with time, using 0.14 wt\% of bentonite alone at different $\mathrm{pH}$ levels. 


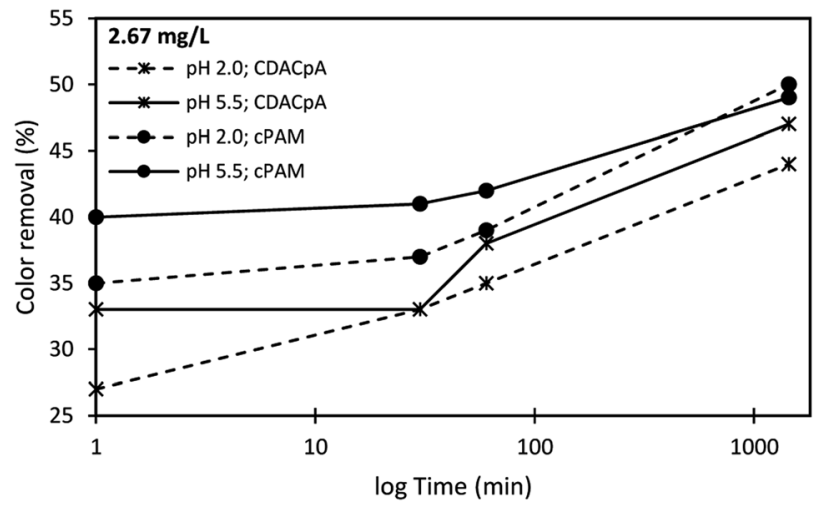

Fig. 14 Duasyn Direct Red color removal using single system with flocculation agent $\left(2.67 \mathrm{mg} \mathrm{L}^{-1}\right.$ of synthetic CPAM or cellulose-based $\mathrm{CDAC}_{\mathrm{p}} \mathrm{A}$ ) at two different $\mathrm{pH}$ levels, 2.0 and 5.5.

in Fig. 15 and 16. The preliminary tests when using single system (polymer alone), were carried out with cationic cellulosebased PEL obtained from bleached pulp $\left(\mathrm{CDAC}_{\mathrm{p}} \mathrm{A}\right)$ and $\mathrm{CPAM}$ (synthetic PEL of similar charge) (see Fig. 14). Due to $\mathrm{pH}$ dependency of the charge of the model colored effluent, different $\mathrm{pH}$ levels were used in the performed trials, to evaluate the flocculation performance of the tested polymers. As it was shown, Duasyn Direct Red is negatively charged (Fig. 7), however with the increase of acidity the charge decreases slightly. It was then important to evaluate the performance of the tested polymers at the initial effluent $\mathrm{pH}$ (5.5) and at slightly acidic $\mathrm{pH}(2.0)$, due to lower stability of the system in the latter conditions.

Fig. 14 shows the color removal results at two different pHs (2.0 and 5.5, the latter being the initial dye $\mathrm{pH}$ ) for $2.67 \mathrm{mg} \mathrm{L}^{-1}$ of $\mathrm{CDAC}_{\mathrm{p}} \mathrm{A}$ or synthetic cPAM, in single systems. The decoloration performance of CPAM was always slightly higher when compared to that of the cellulose-based polymer, for the same $\mathrm{pH}$ level, especially for lower settling times. Moreover, for all performed tests using only flocculant, the color removal after $24 \mathrm{~h}$ was less than $50 \%$. This was the main reason to use the flocculation agents in dual systems with bentonite (see Fig. 15 and 16).

Fig. 15 and 16 show the results obtained at $\mathrm{pH} 2.0$ and 5.5, while using two different concentrations of flocculation agent: $1.33 \mathrm{mg} \mathrm{L}^{-1}$ (procedure A) or $2.67 \mathrm{mg} \mathrm{L}^{-1}$ (procedure B), in dual system with $0.25 \mathrm{wt} \%$ bentonite. In all the presented cases, only for the $\mathrm{pH}$ of 2.0, an adequate color removal was achieved when using cellulose-based flocculation agents. At this $\mathrm{pH}$, decoloration values from 52 to $78 \%$ with procedure $\mathrm{A}$, or from 53 to $85 \%$ with procedure $\mathrm{B}$ were obtained. Increasing polymer concentration led in most of the cases to some increase of performance, especially regarding the initial period of color removal, being the removal faster when the bio-PELs concentration was increased.

Typically, at the tested pHs (below $\mathrm{pH} 8.0),{ }^{30}$ bentonite is positively charged, even if only for very acidic $\mathrm{pH}(<3.5)$ the charge is substantially different from zero and becomes highly positive. Thus, at low $\mathrm{pH}$ the interaction of bentonite with the
A
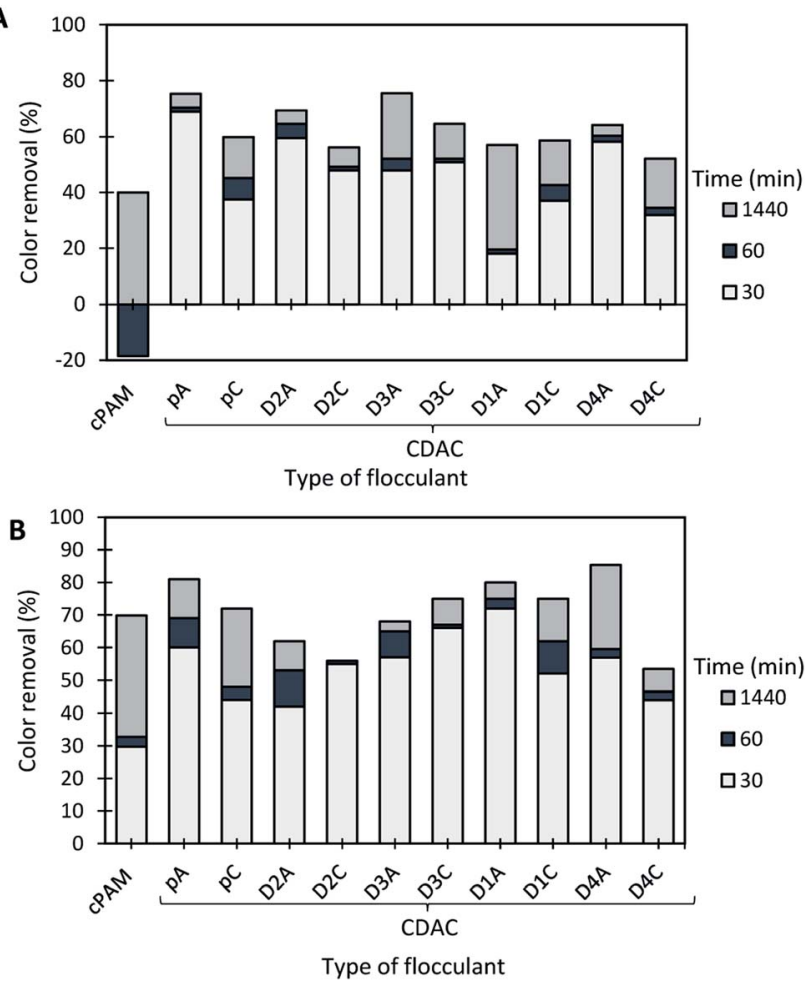

Fig. 15 Duasyn Direct Red color removal with time, using cellulosebased flocculation agents from different sources in dual system with bentonite at $\mathrm{pH}$ 2.0. Procedure A: $0.25 \mathrm{wt} \%$ of bentonite followed by $1.33 \mathrm{mg} \mathrm{L}^{-1}$ of flocculant. Procedure B: $0.25 \mathrm{wt} \%$ of bentonite and $2.67 \mathrm{mg} \mathrm{L}^{-1}$ of flocculant. Cationic synthetic PAM in dual system with bentonite was used as reference.

negatively charged molecules of Duasyn Direct Red (Fig. 8) is favored. Further addition of polymer allows bridging between bentonite-dye complexes, growth of flocs and their faster settling over time, comparing to the single system presented in Fig. 14. Referring to the tests at pH 5.5 (Fig. 16), dye removal when using bentonite plus CDAC was inexistent due to the low charge of bentonite (only slightly positive) ) $^{30}$ and to the high stability of the dye (see Fig. 8). Accordingly, for this pH, using $\mathrm{CDAC}_{\mathrm{p}} \mathrm{A}$ alone resulted in higher removal (around 47\%) than when combining bentonite with CDAC (compare Fig. 14 and 16).

In summary, after the bentonite complexation with the dye, some sites were still left for polymer adsorption and effective flocculation. Moreover, changing the concentration of used PEL from $1.33 \mathrm{mg} \mathrm{L}^{-1}$ to $2.67 \mathrm{mg} \mathrm{L}^{-1}$ (procedure A compared to B), did not show a large influence on final decoloration efficiency except on what concerns the speediness of decoloration. All tested bio-PELs worked well for the treatment of Duasyn Direct Red model effluent at low $\mathrm{pH}$, including those obtained from pulps with higher lignin content, such as $\mathrm{CDAC}_{\mathrm{D} 4} \mathrm{~A}$. Also, CDACs showed similar or better performance than the reference cPAM.

It is worth stressing, that the predominant flocculation mechanism in the performed experiments must be interaction with bentonite (especially adsorption) followed by bridging 
A
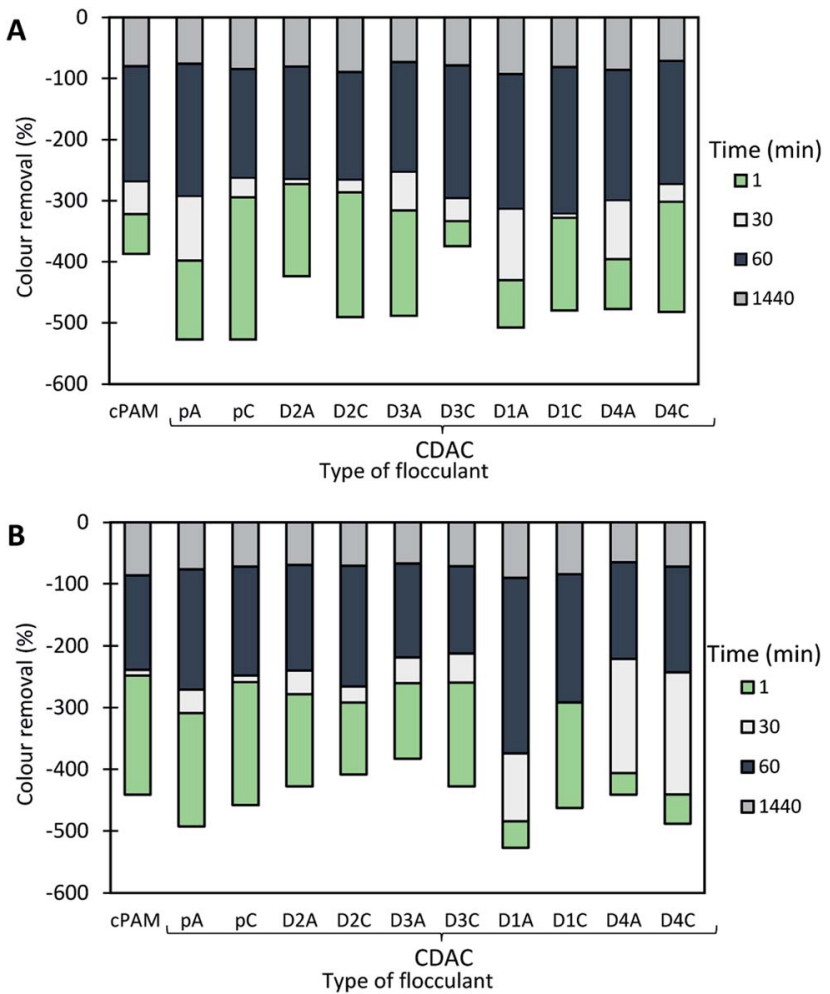

Fig. 16 Duasyn Direct Red color removal with time, using cellulosebased flocculation agents from different sources in dual system with bentonite at $\mathrm{pH} 5.5$ Procedure A: $0.25 \mathrm{wt} \%$ of bentonite followed by $1.33 \mathrm{mg} \mathrm{L}^{-1}$ of flocculant. Procedure B: $0.25 \mathrm{wt} \%$ of bentonite and $2.67 \mathrm{mg} \mathrm{L}^{-1}$ of flocculant. Cationic synthetic PAM in dual system with bentonite was used as reference.

through the polymer chains. Also, success of dye removal showed to be highly $\mathrm{pH}$ dependent, due to ionization of functional groups in the chemical structure of dye, as well as due to the effect of $\mathrm{pH}$ in the bentonite additive, used in the clarification procedure.

\section{Conclusions}

In this work, water-soluble cationic cellulose-based polyelectrolytes were synthesized from a wide range of Eucalyptus pulps differing in chemical composition (cellulose, hemicellulose and lignin contents), in a two-step reaction, overcoming the need to use more pure cellulosic materials (without lignin) as is common in the literature. The overall results showed that the periodate oxidation followed by the quaternary ammonium cationization, with Girard's reagent T, was possible to implement for various types of Eucalyptus lignocellulosic raw materials. Applying different GT/aldehyde molar ratios allows to obtain different substitution degrees by the cationic units, and, typically the charge density of the final product increases with the increase of the used GT reagent up to a certain limit. The zeta potential values of the PELs were in the range of 40 to $62 \mathrm{mV}$ and the lowest values were obtained for the PELs produced from the raw material with the highest complexity (D4 corresponding to the pulp with larger lignin content and lower cellulose content).

Also, in this work, the water-soluble cationic cellulose-based PELs were used, for the first time, as flocculants for dyes removal, having in mind that dye-containing effluents are very harsh still requiring further attention and more eco-friendly approaches. Typically, a dual system with bentonite, was found to be efficient for the color removal of the two tested model colored effluents: Duasyn Direct Red and Basic Green 1. The development of the method included the study of the influence of polyelectrolyte dosage, the incorporation of a dual system with addition of an inorganic agent (bentonite), as well as the assessment of the influence of $\mathrm{pH}$ on the clarification efficiency and color removal. The dual system with addition of the inorganic agent, followed by the flocculant, was generally required to obtain high color removals, even if the cationic cellulosic PELs, alone, already led to dye removals around $50 \%$. Additionally, working at acidic $\mathrm{pH}$ conditions, allowed to obtain higher color removals and rapid flocculation kinetics.

Overall, it can be concluded that all cationic cellulose-based PELs, including those obtained from the lignocellulosic pulp with higher kappa number (higher lignin content) provided good results in the decoloration tests. Often, similar or better results were obtained while using the natural-based flocculants compared to the commercial polyacrylamide normally used for this purpose (at the same $\mathrm{pH}$ and flocculant dosage).

In summary, a new range of cationic cellulose-based materials, obtained from wood wastes using mild reaction conditions, can thus be proposed and considered for the treatment of colored effluents. Using the proposed bio-flocculants as wastewater treatment agents, can be considered as a promising valorization of natural wastes (Eucalyptus wood wastes) with a positive environmental impact, namely considering the biodegradable nature of these polymers.

\section{Conflicts of interest}

There are no conflicts to declare.

\section{Acknowledgements}

The authors would like to thank financial support from Marie Curie Initial Training Networks (ITN) - European Industrial Doctorate (EID), through Grant agreement FP7-PEOPLE-2013ITN-604825 and from the Portuguese Science and Technology Foundation (Pest/C/EQB/UI0102/2013), co-financed by the European Regional Development Fund (ERDF) through the program COMPETE (POFC).

\section{References}

1 A. Bhatnagar, M. Sillanpää and A. Witek-Krowiak, Chem. Eng. J., 2015, 270, 244-271.

2 V. Ajao, H. Bruning, H. Rijnaarts and H. Temmink, Chem. Eng. J., 2018, 349, 622-632.

3 D. Klemm, B. Heublein, H. P. Fink and A. Bohn, Angew. Chem., Int. Ed., 2005, 44, 3358-3393. 
4 R. Aguado, A. F. Lourenço, P. J. Ferreira, A. Moral and A. Tijero, Cellulose, 2017, 24, 3015-3027.

5 L. Yan, H. Tao and P. R. Bangal, Clean: Soil, Air, Water, 2009, 37, 39-44.

6 J. Sirviö, A. Honka, H. Liimatainen, J. Niinimäki and O. Hormi, Carbohydr. Polym., 2011, 86, 266-270.

7 H. Liimatainen, J. Sirviö, O. Sundman, M. Visanko, O. Hormi and J. Niinimäki, Bioresour. Technol., 2011, 102, 9626-9632.

8 J. Liesiene, Cellulose, 2010, 17, 167-172.

9 L. Halab-Kessira and A. Ricard, Eur. Polym. J., 1999, 35, 10651071.

10 X. Liu, L. Wang, X. Song, H. Song, J. R. Zhao and S. Wang, Carbohydr. Polym., 2012, 90, 218-223.

11 J. Sirvio, U. Hyvakko, H. Liimatainen, J. Niinimaki and O. Hormi, Carbohydr. Polym., 2011, 83, 1293-1297.

12 U. J. Kim, S. Kuga, M. Wada, T. Okano and T. Kondo, Biomacromolecules, 2000, 1, 488-492.

13 T. Nikolic, M. Kostic, J. Praskalo, B. Pejic, Z. Petronijevic and P. Skundric, Carbohydr. Polym., 2010, 82, 976-981.

14 D. Rajalaxmi, N. Jiang, G. Leslie and A. J. Ragauskas, Carbohydr. Res., 2010, 345, 284-290.

15 Q. X. Hou, W. Liu, Z. H. Liu and L. L. Bai, Ind. Eng. Chem. Res., 2007, 46, 7830-7837.

16 T. Aimin, Z. Hongwei, C. Gang, X. Guohui and L. Wenzhi, Ultrason. Sonochem., 2005, 12, 467-472.
17 W. M. Abd El-Rahim and O. A. M. El-Ardy, Desalin. Water Treat., 2011, 25, 39-46.

18 Z. Bouberka, S. Kacha, M. Kameche, S. Elmaleh and Z. Derriche, J. Hazard. Mater., 2005, 119, 117-124.

19 J. R. Aspland, Text. Chem. Color., 1980, 12, 24-26.

20 M. A. Hubbe, K. R. Beck, W. G. O'Neal and Y. C. Sharma, BioResources, 2012, 7, 2592-2687.

21 L. M. Reina and F. Resquin, Eucalyptus Online B. Newsl., 2011, vol. 37, pp. 1-6.

22 J. A. F. Gamelas, M. G. Evtyugina, I. Portugal and D. V. Evtuguin, RSC Adv., 2012, 2, 831-839.

23 D. W. Clayton, Sven. Papperstidn., 1963, 28, 115-124.

24 J. A. F. Gamelas, A. R. Gaspar, D. V. Evtuguin and C. Pascoal Neto, Appl. Catal., A, 2005, 295, 134-141.

25 K. Grenda, J. Arnold, J. A. F. Gamelas and M. G. Rasteiro, Water Sci. Technol., 2017, 76, 1490-1499.

26 Y. Zhang and P. Fatehi, Ind. Crops Prod., 2019, 130, 81-95.

27 H. Liimatainen, J. Sirviö, A. Haapala, O. Hormi and J. Niinimäki, Carbohydr. Polym., 2011, 83, 2005-2010.

28 H. Liimatainen, J. Sirviö, O. Sundman, O. Hormi and J. Niinimäki, Water Res., 2012, 46, 2159-2166.

29 A. Balea, M. C. Monte, E. Fuente, J. L. Sanchez-Salvador, A. Blanco and C. Negro, Environ. Sci.: Water Res. Technol., 2019, 5, 1558-1567.

30 D.-S. Kim, Environ. Eng. Res., 2003, 8, 222-227. 